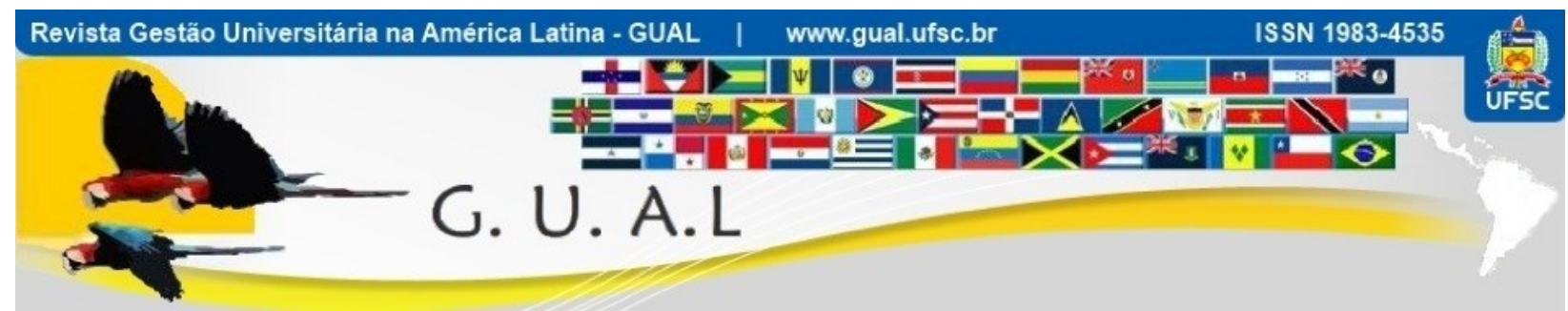

DOI: http://dx.doi.org/10.5007/1983-4535.2016v9n4p45

\title{
A CONTRIBUIÇÃO DO CURSO DE GESTÃO PÚBLICA DA UNIVERSIDADE FEDERAL DO PAMPA - UNIPAMPA PARA A MODERNIZAÇÃO DA ADMINISTRAÇÃO PÚBLICA EM SANTANA DO LIVRAMENTO/RS
}

\section{CONTRIBUTION OF THE UNDER GRADUATION IN PUBLIC MANAGEMENT OF THE UNIVERSIDADE FEDERAL DO PAMPA - UNIPAMPA TO THE MODERNIZATION OF PUBLIC ADMINISTRATION IN THE CITY OF SANTANA DO LIVRAMENTO/RS}

Raquel Duarte Preste, Graduada Universidade Federal do Pampa - UNIPAMPA raquelpcarpes@gmail.com

Sebastião Ailton da Rosa Cerqueira-Adão, Doutor Universidade Federal do Pampa - UNIPAMPA sebacerqueira@hotmail.com

Recebido em 04/dezembro/2015

Aprovado em 14/outubro/2016

Sistema de Avaliação: Double Blind Review

Esta obra está sob uma Licença Creative Commons Atribuição-Uso. 


\title{
RESUMO
}

Este estudo teve como objetivo identificar a contribuição do Curso de Gestão Pública da Universidade Federal do Pampa - UNIPAMPA para a modernização da Administração Pública em Santana do Livramento. Para o desenvolvimento desta pesquisa utilizou-se o método de estudo de caso que foi desenvolvido na UNIPAMPA. A coleta de dados foi realizada por meio de entrevistas semiestruturadas e as análises foram desenvolvidas sob o viés qualitativo. Como resultado, identificou-se que, hoje a contribuição do curso de Gestão Pública da UNIPAMPA tem sido essencial para a busca de melhorias na prestação de serviços da Prefeitura Municipal de Santana do Livramento, sendo esta instituição a mais beneficiada tanto com a produção acadêmica do Curso de Gestão Pública, quanto com o aproveitamento de egressos. A urgente necessidade de qualificar e capacitar os gestores públicos locais fez surgir o interesse por formação continuada dos gestores públicos locais, sendo atualmente ofertado pela UNIPAMPA também o Curso de Pós-graduação Lato Sensu em Gestão Púbica.

Palavras-chave: Administração pública. Gestão pública. Ensino superior. UNIPAMPA.

\begin{abstract}
This study aimed to identify the Contribution of the under graduation in public management of the Universidade Federal do Pampa - UNIPAMPA to the Modernization of public administration in the city of Santana do Livramento/RS. For the development of this research was used the case study method performed in UNIPAMPA. Data collection was made through semi-structured interviews and analyzes were developed from a qualitative bias. As a result it was find that, today the contribution of the under graduation in public management UNIPAMPA has been essential to seek improvements in the proving services in the Municipality of Santana do Livramento, to be the institution the most benefited for academic production in the course of Public Management, as with the use of graduates. The urgent need to qualify and to train the public managers of the city, has increased the interest in the continued training of local public sector manager, and today UNIPAMPA offer the course of Specialization on Public Management also.
\end{abstract}

Keywords: Public administration. Public management. Higher education. 


\section{A CONTRIBUIÇÃO DO CURSO DE GESTÃO PÚBLICA DA UNIVERSIDADE FEDERAL DO PAMPA - \\ UNIPAMPA PARA A MODERNIZAÇÃO DA ADMINISTRAÇÃO PÚBLICA EM SANTANA DO \\ LIVRAMENTO/R \\ DOI: http://dx.doi.org/10.5007/1983-4535.2016v9n4p45}

\section{INTRODUÇÃO}

Quando se fala do setor público no Brasil, existe uma percepção de que as pessoas que trabalham neste setor são acomodadas e despreparadas. Paira uma ideia de que boa parte dos processos é desenvolvido por meio do "jeitinho brasileiro", em que prevalece a corrupção e as negociatas. Neste contexto, sente-se, cada vez mais, a necessidade de se profissionalizar a Administração Pública e neste sentido observa-se que uma das formas de se aparelhar melhor o estado pode ser a partir dos cursos de graduação em Gestão Pública.

Estruturados de forma multidisciplinar, vê-se que no Brasil os Cursos direcionados para a formação do Gestor Público atendem a várias áreas do conhecimento, como Direito; Economia; Contabilidade; Auditoria; Licitações e Processos; Administração; Projetos; Gestão de Pessoas; Sistemas de Informações; Sociologia; Filosofia e Ética Profissional e coloca o Gestor como o profissional capaz de atender às demandas da população, atuando através da aplicação e controle de ferramentas que possibilita melhorias na administração pública. Cursos que apresentam currículos bem estruturados nos conceitos base de áreas do conhecimento como a Administração; Contabilidade; Economia e Direito (entre outros) e foco nas Organizações Públicas e que têm como objetivo qualificar os profissionais que vão atuar nestas organizações.

Essa capacitação confere ao Gestor Pública o conhecimento necessário a sua atuação na administração pública. Mas, para que se tenha uma visão real do papel desse profissional, são necessárias algumas averiguações, as quais esse estudo se propõe, conforme o Catálogo Nacional dos Cursos Superiores de Tecnologia, os Cursos de Gestão Pública formam o tecnólogo em Gestão Pública que atuará em instituições públicas, nas esferas federal, estadual e municipal. Ainda conforme descrito no Catálogo Nacional, vê-se que as atividades do Gestor Público centram-se no planejamento, implantação e gerenciamento de programas e projetos de políticas públicas. Para essa formação em Gestão Pública, há uma forte ênfase nas regulamentações legais, sendo que o egresso dos Cursos apresentam como perfil profissional habilidades e competências que buscam otimização da capacidade de governo. Sendo que, para tal formação, há a necessidade de uma carga horária mínima de 1.600 horas a ser desenvolvidas por meio de atividades teóricas e práticas.

Contemplando o atual cenário da gestão pública brasileira, onde somado aos problemas econômicos, financeiros, sociais e políticos tem sido constantes as manifestações 
sociais, documentadas em jornais e noticiários nacionais e internacionais com reivindicações por melhorias nos órgãos públicos, menos corrupção e mais seriedade por parte do poder público. Tais manifestações demonstram uma visível inconformidade da população, quanto à utilização e distribuição desigual das finanças públicas.

Observando-se, por exemplo, o Movimento Vem Para Rua, percebe-se que o clamor do povo ganha uma nova conotação, quando se identifica uma significativa participação de jovens estudantes, fator esse que, de maneira ainda informal, pois não existem estudos para corroborar a afirmação, pode ser associado ao acréscimo no ingresso de jovens ao ensino superior. É possível construir essa relação de maior acesso e de busca por informações, conhecimento e participação que estes jovens têm em função do ingresso em instituições universitárias e das mudanças que levam a percepção de uma sociedade que em meio a insuficiência e mau uso dos recursos públicos, e uma política de descontinuidades e defesa de interesses minoritários, espera e tenta se articular em prol de uma nova administração pública, com divulgação e transparência dos atos realizados por seus governantes.

Para Paula (2010), dimensiona-se insuficiente a mera aplicação de novas técnicas administrativas ou a contribuição das mais modernas tecnologias, se na sua aplicação, se para a implantação, condução e controle destas não houver um profissional, especificamente capacitado, eticamente comprometido e conhecedor da estrutura pública com todas as implicações, políticas estruturais e sociais de seu âmbito organizacional, capaz de garantir ou comprometer todo um processo de mudanças ou adequações.

Com base no exposto acima, este estudou buscou responder a seguinte questão: Qual a contribuição do Curso de Gestão Pública da UNIPAMPA para a modernização da Administração Pública em Santana do Livramento na percepção de professores, exalunos e secretários municipal?

A partir do problema acima estabelecido, elaborou-se o objetivo geral: identificar a contribuição do Curso de Gestão Pública da UNIPAMPA para a modernização da Administração Pública em Santana do Livramento na percepção de professores, exalunos e secretários municipal.

Os Objetivos específicos elaborados para esse estudo foram:

a) Diferenciar Administração Pública e Gestão Pública;

b) Estabelecer histórico da Implantação dos Cursos de Graduação em Gestão Pública no Brasil; 


\section{c) Identificar o histórico da modernização da Gestão Pública no Brasil a partir da} década de 90.

Este estudo justifica-se pelo fato de reunir conceitos da Gestão Pública e abordar as possíveis mudanças necessárias em termos de eficiência e eficácia. Buscou-se aqui fazer a relação entre os princípios e técnicas disseminadas em um curso de graduação que possam proporcionar a qualificação de atores com base em conhecimentos capazes de contribuir para a modernização da estrutura administrativa.

O profissional de Gestão Pública, que adquire conhecimentos para gerir programas, projetos e ações públicas parece levar para as instituições das diferentes esferas públicas, ou seja, União, estados e municípios uma nova forma de pensar e de fazer que, parece, permitem uma substancial mudança em termos de alcance de objetivos e metas do setor público.

Com este artigo busca-se contribuir para uma mudança de atitude em relação às questões menos técnicas e mais políticas que envolvem a coisa pública, trazendo este estudo uma contribuição para que se dissemine uma nova visão da Gestão Pública baseada na competência e impessoalidade.

\section{REFERENCIAL TEÓRICO}

Neste referencial teórico buscou-se abordar temas como a diferenciação entre a Administração Pública e a Gestão Pública e a implantação dos cursos de graduação em gestão pública no Brasil, buscando elementos para a análise e conclusões deste artigo.

\subsection{DIFERENÇAS ENTRE ADMINISTRAÇÃO PÚBLICA E GESTÃO PÚBLICA}

A partir de uma análise na literatura é possível perceber que ao longo dos anos houve uma transformação no entendimento, percepção e aplicabilidade da gestão no âmbito público, ou da Administração Pública. E, no intuito de compreender a importância do Curso de Gestão Pública, percebe-se, primeiramente que se faz necessário estabelecer uma diferenciação clara entre o que é Administração Pública e o que é Gestão Pública. Embora muito se fale a respeito do tema, sua real definição não é de amplo domínio público.

Buscando-se sanar a questão supracitada, inicialmente delimita-se uma definição para gestor e administrador. Mediante o viés de Silva (2011), o gestor ou administrador público é aquele designado, eleito ou nomeado formalmente, conforme previsto em lei e/ou em regulamento específico, para exercer a administração superior de órgão ou entidade integrante 


\section{A CONTRIBUIÇÃO DO CURSO DE GESTÃO PÚBLICA DA UNIVERSIDADE FEDERAL DO PAMPA - UNIPAMPA PARA A MODERNIZAÇÃO DA ADMINISTRAÇÃO PÚBLICA EM SANTANA DO LIVRAMENTO/R \\ DOI: http://dx.doi.org/10.5007/1983-4535.2016v9n4p45}

da Administração Pública. Ainda com base neste autor, vê-se que a Administração superior engloba a totalidade de atividades que se referem à definição de políticas e metas de atuação do ente público e a tomada de decisões, visando assim atingir os objetivos e finalidades estabelecidas nas normas legais que regulamentam sua atuação.

Desta forma, Nascimento (2010) identifica que a nova administração pública representa um modelo de administração emergente que tem por objetivo identificar e equacionar a crise do Estado e apontam como suas principais características as seguintes: busca pela revitalização da função pública e a profissionalização dos servidores governamentais; busca pela competência institucional, com ênfase na regulação e na proteção social; foco em resultados, mediante avaliação permanente; direcionamento da administração para o cidadão-usuário; simplificação de procedimentos; transparência e acesso às informações públicas; arranjos institucionais que visam à representação dos interesses coletivos e ao controle social; a utilização pelo Estado de tecnologias emergentes de informação; promoção de um empreendedorismo digital; busca pela equidade e diminuição de desigualdades sociais patrocinadas pela ação governamental.

Analisando-se os conceitos de Bergue (2010), vê-se que o termo gestão pode ser compreendido como sinônimo de administração. Administrar, para o autor, constitui um processo complexo com diversas definições possíveis. Uma delas seria executar, de forma contínua e virtuosa, o processo administrativo. Sendo o processo administrativo, para esse autor, resultante da interação dos elementos: planejamento, organização, direção e controle. As ações de gestão estariam assim associadas a um ou mais elementos do ciclo administrativo.

Nascimento (2010) define Gestão Pública em um contexto mais abrangente. Para o autor, gestão é a prática que, aprimorada, produzirá determinados fins, buscando atender as principais demandas da sociedade. Como por exemplo: a redução da pobreza, melhoria na educação, aumento da competitividade econômica e da conservação dos recursos naturais, preservação e expansão da cultura, devendo o setor público ter seu desenvolvimento social e econômico voltado a atender esses objetivos. Promovendo a melhoria das organizações e dos métodos, da informação gerencial, da capacitação das pessoas através da participação estratégica da gestão pública em um amplo projeto de desenvolvimento.

Ainda, Williams (2010) incorpora no conceito itens como: liderança, motivação e controle ao processo administrativo. Para o autor, administrar é a forma como se planeja a 


\section{A CONTRIBUIÇÃO DO CURSO DE GESTÃO PÚBLICA DA UNIVERSIDADE FEDERAL DO PAMPA - \\ UNIPAMPA PARA A MODERNIZAÇÃO DA ADMINISTRAÇÃO PÚBLICA EM SANTANA DO \\ LIVRAMENTO/R \\ DOI: http://dx.doi.org/10.5007/1983-4535.2016v9n4p45}

organização de tarefas, organiza a empresa para que tenha eficiência e eficácia, liderando, motivando os funcionários, e criando controles para assegurar o cumprimento de planos e metas.

$\mathrm{O}$ atual contexto da administração pública traz uma amplitude e complexidade maior ao âmbito da gestão, aqui apresentados por Nascimento (2010), que afirma que o papel profissional, baseado no modelo tradicional, burocrático e weberiano não atende às necessidades sociais e as novas formas de governança e de gestão. Onde a questão da mobilização de recursos externos, através da parceria do Estado com o terceiro setor e a sociedade civil, torna-se importante para a gestão dos recursos públicos, pois essa nova realidade requer que o Estado atue dentro de um novo modelo de gestão, que demanda um novo perfil profissional.

Amaral (2010) parece acreditar que as teorias que tratam de governo e gestão pública incorporaram novos aspectos, revalorizaram conceitos e práticas e trazem novas possibilidades de tratamento a temas tradicionais.

Nesse contexto, Lynn Jr. (2010) nos apresenta as seguintes considerações referentes ao tema: a) O senso comum em relação à Gestão Pública é relativamente objetivo; b) Bons gestores públicos, quaisquer que sejam seus cargos e responsabilidades, são homens e mulheres com habilidades e temperamento necessários para organizar, motivar e orientar as ações de outras pessoas que façam parte ou não do governo, na criação e execução de objetivos que justifiquem o uso da autoridade pública.

Para Dias (2002, p.10 e 11), considera-se correto "gestão da produção e administração na produção", de tal forma que a gestão incorpora a administração, tornando-a função necessária ao seu desempenho. Assim para o autor, administração é planejar, organizar, dirigir e controlar pessoas para atingir de forma eficiente e eficaz os objetivos de uma organização. Enquanto que a gestão seria a utilização de funções; técnica, contábil, financeira, comercial, segurança e administração, e os conhecimentos de áreas como a psicologia, antropologia, estatística, mercadologia, ambiental e outras, para através das pessoas atingirem os objetivos da organização de forma eficiente e eficaz.

Segundo Falconer (1997) desde 1980, o estudo da administração pública busca desmistificar a mudança de paradigma de princípios de administração pública àqueles de gestão pública. O movimento que hoje é visto como um progresso natural consistia em um conjunto de doutrinas de uma boa administração, que enfatizava hierarquias ordenadas, 
burocracias despolitizadas e a eliminação da duplicação, do que tem sido descrito, como a "nova gestão pública".

Hood (1996) identifica a "nova gestão pública", através de temas que visam à reforma da organização e de procedimentos no setor público, que buscam torná-lo mais competitivo e eficiente no uso de recursos e prestação de serviços, preocupando-se com a prestação de serviços à população e com as relações entre Estado e cidadãos.

Após as diferenças entre Administração Pública e Gestão Pública a seguir passa-se a apresentar o histórico da Implantação dos Cursos de Graduação em Gestão Pública no Brasil.

\subsection{A IMPLANTAÇÃO DOS CURSOS DE GRADUAÇÃO EM GESTÃO PÚBLICA NO BRASIL}

No intuito de entender-se o processo de implantação dos cursos de graduação em gestão pública no Brasil, faz-se necessário antes buscar conhecer os principais fatores que motivaram a evolução deste tipo de Curso. É este um dos itens que se buscou demonstrar neste estudo, além de um breve histórico dos cursos e o caminho percorrido pela administração pública dentro dos principais modelos administrativos no país, e da gestão pública, a partir da reforma gerencial, na busca de capacitação e qualificação a seus servidores, como forma de empreender qualidade e eficiência ao serviço público.

Dentre os principais motivadores no processo evolutivo dos cursos de gestão pública, Girard (2009), apresenta o conhecimento como fator essencial ao desenvolvimento, sendo o responsável por tornar as organizações mais competitivas. Onde o ambiente organizacional aprende a gerar conhecimento, e a transformar este em novas tecnologias, inovação, sistemas, produtos e serviços. Neste processo, afirma o autor, as pessoas passam a ser cada vez mais importantes para a estratégia das organizações.

Tal posicionamento parece possuir o assentimento de Bittencourt e Zouain (2010), que consideram como elemento básico do progresso, tanto nos países desenvolvidos, como naqueles em desenvolvimento, além de um qualificado corpo de gestores públicos, auxiliares de funções executivos plenamente capacitados. Onde os setores responsáveis por cada nação, preocupam-se em buscar um serviço público eficaz, idealizado em bases técnicas e científicas, que consiga atingir um grau de excelência condizente com os desafios de sua época e necessidades. 


\section{A CONTRIBUIÇÃO DO CURSO DE GESTÃO PÚBLICA DA UNIVERSIDADE FEDERAL DO PAMPA - \\ UNIPAMPA PARA A MODERNIZAÇÃO DA ADMINISTRAÇÃO PÚBLICA EM SANTANA DO \\ LIVRAMENTO/R \\ DOI: http://dx.doi.org/10.5007/1983-4535.2016v9n4p45}

Levy (1997), afirma ser necessário converter as organizações públicas de forma a torná-las mais ativas, menos hierarquizadas, comprometidas com seu corpo de servidores e transparentes ao acompanhamento estatal e social. O perfil de gestão dessas instituições deve entender conhecimentos e comportamentos, capazes de realizar processos de transformação nas mesmas e estar de forma permanente preparado às oscilações externas.

Torna-se necessário, portanto, de acordo com o autor, acompanhamento da modernização do Estado, através de uma nova visão de gestão, conjuntamente a uma política de formação permanente, que prepare seu pessoal, técnico-administrativo e gerencial, para o melhor desempenho da missão. Como forma de proporcionar qualificação, capacitação e treinamento ao setor público, foram criados as assim denominadas "Escolas de Governo".

Zouain (2010) dispõe essas instituições em dois grupos; um primeiro, com a missão de capacitar, em diversos níveis, ligados às áreas e carreiras específicas de atuação do Estado. No segundo grupo, reúnem-se instituições que além de trabalharem com o setor público, não possuem vinculação específica às carreiras de Estado. Trabalhando com servidores distribuídos em todos os níveis burocráticos.

Como forma de regulamentar e oficializar o funcionamento dessas instituições, o artigo 39 da Constituição Federal de 1988 estabelece à União, aos Estados e ao Distrito Federal que mantenham "escolas de governo para formação e aperfeiçoamento dos servidores públicos". Passando muitas instituições estaduais a se auto classificarem como Escolas de Governo. Neste contexto é criada pelo governo federal, a Escola Nacional de Administração Pública - ENAP.

As primeiras iniciativas de implementação de escolas de governo no Brasil, aconteceram a partir dos anos de 1980 e início de 1990, em belo Horizonte, em São Paulo, em Porto Alegre, em Curitiba, no Rio de Janeiro e em Brasília, projeto este que tem encontrado grandes dificuldades, segundo Bittencourt e Zouain, de se consolidar nacionalmente.

Gaetani (1994) registra que a ideia das escolas de governo possui reflexos sociais, tendo suporte na experiência de outros países e na deterioração da aração pública nacional, a permanência do ideal weberiano de burocracia.

De acordo com a análise feita por Bittencourt e Zenouin (2010), a definição do real papel das escolas será conhecida no contexto das reformas gerenciais do setor público. Onde apesar de originadas no propósito de formar a futura elite burocrática da administração 


\section{A CONTRIBUIÇÃO DO CURSO DE GESTÃO PÚBLICA DA UNIVERSIDADE FEDERAL DO PAMPA - \\ UNIPAMPA PARA A MODERNIZAÇÃO DA ADMINISTRAÇÃO PÚBLICA EM SANTANA DO \\ LIVRAMENTO/R \\ DOI: http://dx.doi.org/10.5007/1983-4535.2016v9n4p45}

pública têm hoje o diferente propósito de capacitar os quadros existentes, principalmente em nível gerencial.

Os Cursos Superiores de Tecnologia começaram a ser implantados no Brasil a partir da década de 1970. Buscando uma melhor formação e qualificação aos trabalhadores, de forma a atender a aumentada demanda, por educação básica e qualificação profissional continuada, provocada por um período de forte industrialização e modernização. A expansão dos Cursos Superiores de tecnologia (CSTs) deve-se, segundo estudo apresentado Takahashi, (2010) às reformas no sistema educacional e de forma mais ampla a situação socioeconômica e política do país. Assim, visando alinhar as estratégias educacionais ao contexto internacional e às pressões da economia baseada no conhecimento para a inserção na chamada economia globalizada.

De acordo com o estudo, o incentivo à educação profissional de nível superior dos últimos dez anos no Brasil deve-se a fatores como, a busca de continuidade de estudos por parte do grande número de alunos formados no ensino médio; à pressão empregada por parte da economia baseada no conhecimento (EBC), onde com base nas informações e no conhecimento são enfatizadas novas características da economia a ponto de caracterizar, segundo Foray e Lundvall(1996) uma nova era histórica.

No Brasil, a Nova Lei de Diretrizes e Bases, Lei $\mathrm{n}^{\mathrm{o}}$ 9.394/96, e posteriores regulamentações, permitiram uma reciclagem à educação profissional e através do estímulo oferecido pela Secretaria de Educação Profissional e Tecnológica - Setec/MEC, aos Cursos Tecnólogos, uma nova dimensão de formação superior ao Brasil. A partir de então foram credenciados os primeiros centros de educação tecnológica - CET's e renovados os cursos de instituições públicas existentes.

Nos últimos cinco anos houve um considerável acréscimo na oferta de vagas, alunos matriculados e instituições ofertantes dos CST's no Brasil, segundo Takashasi (2010). Tais cursos voltados à formação para o trabalho, gestão de produção e serviços e à inovação científica e tecnológica, distinguem-se das graduações tradicionais por sua proposta e propósitos. Entendem a autora que enquanto os Cursos tecnólogos buscam atender a demanda por uma área específica de conhecimento, caracterizada pela rapidez, foco e flexibilidade, as outras modalidades buscam formar generalistas. Estando todos aptos a dar continuidade a seus estudos em nível de pós-graduação. 


\section{A CONTRIBUIÇÃO DO CURSO DE GESTÃO PÚBLICA DA UNIVERSIDADE FEDERAL DO PAMPA - \\ UNIPAMPA PARA A MODERNIZAÇÃO DA ADMINISTRAÇÃO PÚBLICA EM SANTANA DO \\ LIVRAMENTO/R \\ DOI: http://dx.doi.org/10.5007/1983-4535.2016v9n4p45}

Definidos pelo Parecer CNE/CES n436/2001 os CST’s, são cursos de graduação com características especiais, bem distintos dos tradicionais e cujo acesso se fará por processo seletivo, de acordo com as instituições que os ministrem e obedecendo a diretrizes curriculares nacionais a serem aprovadas pelo Conselho Nacional de Educação.

Enquanto formação Menino (2011) entende que os processos de inovação tecnológica e disseminação do desenvolvimento das habilidades e conhecimentos humanos, devem ser articulados conjuntamente, visando alcançar os objetivos propostos. Dentre os principais objetivos dos cursos de graduação em tecnologia, Fourez (1995) destaca a busca de novos conhecimentos e o incentivo à pesquisa.

De acordo com o estudo apresentado por Takahashi (2010), a partir da nova LDB, em termos gerais o curso de educação profissional tecnológica de graduação vem crescendo e se firmando, tanto na rede de ensino pública, quanto privada. Tendo ganhado gradativo reconhecimento social e espaço no mercado de trabalho. Tal crescimento pode ser observado na oferta dos cursos bacharelados na área de administração, também acontece nos cursos tecnológicos, ou CST's, em gestão.

Com relação a censos anteriores, dados comprovam uma intensa expansão da educação superior no Brasil, principalmente nas instituições privadas (INEP, 2008). Em cumprimento ao Decreto $\mathrm{n}^{\circ} 5.773 / 06$, com a finalidade de aprimorar e fortalecer os cursos superiores de tecnologia é apresentado pelo Ministério da Educação o Catálogo Nacional de Cursos Superiores de Tecnologia, que busca servir de referência aos educadores, estudantes, instituições ofertantes, redes de ensino, entidades representativas de classes, empregadores e o público em geral.

Após abordar-se a implantação dos Cursos de Gestão Pública no Brasil, observando-se a sua importância à luz dos autores, a seguir passa-se a abordar a modernização da Gestão Pública no Brasil.

\subsection{A MODERNIZAÇÃO DA GESTÃO PÚBLICA NO BRASIL A PARTIR DA DÉCADA DE 90}

Diversos estudos têm sido publicados, com a finalidade de registrar a história do ensino superior em administração pública no Brasil. A crescente demanda e o aumento na oferta de Cursos Superiores de Tecnologia, especificamente do Tecnólogo em Gestão Pública, 
que neste estudo buscou mostrar sua evolução, nos diferentes momentos e modelos da administração pública no país.

Os novos caminhos da gestão pública no Brasil podem-se assim dizer de acordo com os dados dos autores que embasaram este referencial, parecem ter tido considerável avanço nas últimas décadas, principalmente após o Plano Diretor da Reforma do Aparelho do Estado apresentado pelo então ministro Bresser Pereira.

Assim a história da Gestão Pública no Brasil, segundo Matias (2012), parece estar associada à própria evolução da administração Pública, identificada sua trajetória nos diferentes modelos utilizados na administração pública brasileira, do patrimonialista (1508 a 1930), burocrático (1930 a 1985) ao gerencial, em vigor atualmente.

No entendimento de Matias (2012), a concepção do PDRAE, passa necessariamente pela redefinição do papel do estado. O que denota um prévio reconhecimento das mudanças detectadas em suas obrigações ao longo da história.

Através dessa perspectiva histórica demonstrada pelo autor, a administração pública evoluiu através de três modelos primordiais.

Embora essas três formas se sucedam no tempo, continuam existindo concomitantemente.

Nesse contexto o patrimonialismo funciona como uma extensão do poder dos governantes, e os cargos supridos de acordo com o interesse destes, tornando o nepotismo e a corrupção inerentes a esse tipo de administração. O domínio do capitalismo e da democracia promove a distinção entre mercado e sociedade do Estado. Tornando a administração patrimonialista inaceitável.

A partir da segunda metade do século XIX, no período do Estado liberal, surge o modelo burocrático, na tentativa de combater a corrupção e o nepotismo patrimonialista, tendo como princípios básicos de seu desenvolvimento, a impessoalidade, a hierarquia funcional, a profisssionalização, a ideia de carreira e o formalismo.

Caracterizado por uma desconfiança prévia nos administradores públicos, e por controles rígidos dos processos como admissão de pessoal, compras e no atendimento as demandas. Matos (2012) apontam como principais neste modelo a ineficiência, a auto referência e falta no atendimento aos cidadãos. 


\section{A CONTRIBUIÇÃO DO CURSO DE GESTÃO PÚBLICA DA UNIVERSIDADE FEDERAL DO PAMPA - \\ UNIPAMPA PARA A MODERNIZAÇÃO DA ADMINISTRAÇÃO PÚBLICA EM SANTANA DO \\ LIVRAMENTO/R \\ DOI: http://dx.doi.org/10.5007/1983-4535.2016v9n4p45}

O modelo Gerencial surgiu na segunda metade do século XX, buscando responder às novas necessidades, geradas da expansão das funções econômicas e sociais do estado, da globalização econômica mundial e do desenvolvimento tecnológico.

Conforme registro de Bresser (1999), a Reforma Gerencial de 1995, surgiu em substituição de um modelo burocrático de administrar, mesclada a práticas patrimonialistas e clientelistas, pelo modelo gerencial, embasado nos princípios da nova gestão pública (new public management). E inspirada nos modelos implantados nos países da OCDE, principalmente na Grã-Bretanha.

Caracterizada pela flexibilização dos processos e regulamentos burocráticos, permitiu um maior grau de autonomia e accountability às agências governamentais e seus gerentes.

A reforma concebida por Bresser (1999) envolveu a descentralização dos serviços sociais para estados e municípios; possibilitou a delimitação mais precisa da área de atuação do Estado, permitindo assim a transferência de atividades para o setor público não-estatal, de produção de bens e serviços para o mercado; a diferenciação entre as atividades a serem executadas por políticos, altos funcionários e as que podem ser delegadas à contratações externas; a separação entre execução e formulação de políticas; as atividades executivas específicas do Estado ganham forma de agências executivas; garantir a responsabilização (accountability) através da administração por objetivos.

Em resposta ao questionamento abordado em seu estudo, Bresser (1999), afirmou que a Reforma administrativa foi aprovada, em detrimento das Reformas Tributárias e da Previdência Social por que; resultou de um debate nacional que persuadiu altos administradores públicos e a opinião pública; respondia a uma real demanda social; possuía clareza de objetivos; tinha claro propósito, principalmente no relativo à mudança no direito de estabilidade e promoveu alianças políticas e compromissos limitados.

O balanço realizado por Abrúcio (2007) ressalta o pioneirismo de Bresser em perceber que as necessidades de mudanças na administração pública mundial, refletiam-se a nível nacional. Muito embora o autor afirme que o então ministro nem sempre tenha conseguido adequar politicamente tais transformações as peculiaridades do país.

Abrúcio (2007) considera como principal mudança promovida por Bresser, a continuidade e aperfeiçoamento da Reforma da Administração Pública, ou seja, a reorganização da administrativa do governo federal, que promoveu grandes melhorias nas informações da administração pública. 


\section{A CONTRIBUIÇÃO DO CURSO DE GESTÃO PÚBLICA DA UNIVERSIDADE FEDERAL DO PAMPA - \\ UNIPAMPA PARA A MODERNIZAÇÃO DA ADMINISTRAÇÃO PÚBLICA EM SANTANA DO \\ LIVRAMENTO/R \\ DOI: http://dx.doi.org/10.5007/1983-4535.2016v9n4p45}

Durante este período, aconteceu o fortalecimento das carreiras de Estado e a realização de inúmeros concursos e a revitalização das capacitações promovidas pela Escola Nacional de Administração Pública.

Abrúcio (2007) aponta às inovações ocorridas na área de políticas públicas, entre elas a criação de mecanismos de avaliação, avanço do controle social, formas de coordenação administrativa e financeira, programas voltados à realidade local e ações Inter setoriais.

No governo Lula, houve segundo Abrúcio (2007) a continuidade de iniciativas como o reforço de algumas carreiras, no campo do governo eletrônico e à Controladoria geral da União, instrumento utilizado no combate a corrupção e ineficiência.

Também merece destaque a ampliação da discussão do Plano Plurianual- PPA com a sociedade a nível nacional.

O autor apresenta como um erro significativo no governo Lula, a incapacidade de estabelecer uma agenda que busque a reforma da gestão pública. Fator prejudicial a um governo que declara buscar um aumento na efetividade das políticas públicas.

Matias (2010), apresenta a relação de causalidade entre os poderes, econômicos, políticos e sociais, diretamente relacionadas à Administração pública. E ressalta o aumento nas demandas por parte da população, por participação social e transparência e qualidade nos serviços públicos prestados, como fator motivador na busca de modernização e melhorias na execução de serviços públicos.

Entendendo-se este como, de acordo por registro de Matias (2010), objetivo final dos governos. Após a apresentação da Modernização da Gestão Pública no Brasil, e sua evolução, de acordo com os dados dos autores que embasaram este referencial. Será apresentada a seguir, a metodologia utilizada neste estudo.

\section{ASPECTOS METODOLÓGICOS}

Nesta etapa apresentam-se os procedimentos metodológicos que foram utilizados para atingir os objetivos da pesquisa. E esta pesquisa caracterizou-se por um estudo exploratório descritivo. Segundo Gil (2010) pesquisa exploratória busca trazer maior familiaridade com o problema, com a finalidade de produzir hipóteses. Por considerar vários aspectos relativos aos fatos e fenômenos estudados, possui um aspecto bastante flexível. Sua coleta de dados pode ocorrer de diversas formas, geralmente relacionado ao levantamento de dados, análise de exemplos que promovam a compreensão e de entrevistas com pessoas com experiência 


\section{A CONTRIBUIÇÃO DO CURSO DE GESTÃO PÚBLICA DA UNIVERSIDADE FEDERAL DO PAMPA - \\ UNIPAMPA PARA A MODERNIZAÇÃO DA ADMINISTRAÇÃO PÚBLICA EM SANTANA DO \\ LIVRAMENTO/R \\ DOI: http://dx.doi.org/10.5007/1983-4535.2016v9n4p45}

prática no assunto. Descritivo, porque, como discorre Sampieri et al (2006) as pesquisas descritivas têm por objetivo descrever situações, acontecimentos, ou seja, demonstra de que forma acontecem determinados fenômenos. Já em seu caráter exploratório diz respeito à investigação.

Cabe ressaltar que o caráter deste estudo é delimitado porque o objetivo da pesquisa estabelece uma descrição de dados sobre os cursos de Gestão Pública no país. E, além disso, também exploratório porque pretende identificar a relevância futura da instalação destes cursos para o bom desenvolvimento da Administração Pública no Brasil. Este estudo apresenta viés qualitativo, que segundo a ótica de Sampieri et al (2006) é utilizado para que seja possível descobrir e refinar as questões de pesquisa, buscando compreender a percepção dos entrevistados sobre o fenômeno estudado. Geralmente baseia-se em métodos de coleta de dados que não utilizam medição numérica.

O método de pesquisa escolhido foi o estudo de caso, tendo como pano de fundo a Universidade Federal do Pampa. Como técnica de coleta de dados utilizou-se fontes de documentos e foram coletados dados junto a entrevistados previamente selecionados, professores do Curso de Gestão Pública da UNIPAMPA, selecionados por sua efetiva participação no Curso de Gestão Pública, egressos do Curso em atividade na administração pública municipal, e Secretários municipais, que tem egressos do Curso de Gestão Pública em atividade na sua Secretaria. Também foram utilizados; livros, artigos, dissertações e teses.

Ao proceder a coleta de dados foram considerados os objetivos do estudo e utilizada a entrevista, como forma de efetuar a coleta de dados. Para Triviños (1987), num estudo qualitativo, a entrevista possui a característica de valorizar a presença do investigador, apresentando perspectivas que permitem ao entrevistado liberdade e naturalidade.

Para o procedimento da coleta de dados foi utilizada entrevista semiestruturada, que segundo Triviños $(1987$, p.146) caracteriza-se por questionamentos básicos embasados em teorias e hipóteses que se relacionam com o tema em análise.

A técnica de análise de dados a ser utilizada neste estudo foi a análise de conteúdo que se apresenta com caráter qualitativo. Tal análise foi realizada a partir do cruzamento dos dados primários e secundários num esforço de fazer-se a relação entre o que disseram os entrevistados e o que disseram os autores.

Depois de descritos o procedimento metodológico deste estudo a seguir passa-se a apresentação, análise e discussão dos dados coletados. 


\section{APRESENTAÇÃO E ANÁLISE DOS DADOS}

Para a realização da coleta dos dados a serem apresentados e analisados neste estudo, foram realizadas pesquisas junto aos professores integrantes do Curso de Gestão pública da UNIPAMPA, selecionados por sua efetiva atuação no Curso, egressos do curso que se encontra em atividade na administração pública do município e gestores públicos municipais, que possuem exercendo atividades em sua Secretaria, egressos do Curso de Gestão Pública, os quais apresentaram as percepções abaixo, percepções estas que foram cruzadas com o pensamento dos autores.

\subsection{DIFERENÇAS ENTRE ADMINISTRAÇÃO PÚBLICA E GESTÃO PÚBLICA}

Ao analisarem-se os dados referentes à concepção do gestor público, quanto a sua forma de inserção no serviço público, verifica-se por parte dos entrevistados 02, 04 e 05 percebeu-se o entendimento de que gestor público é somente aquele formalmente nomeado.

De forma complementar ao pensamento anteriormente mencionado, o entrevistado 05 , afirma considerar fundamental a criação desse cargo e seu preenchimento via concurso público.

Diferente visão apresenta o entrevistado 08, que entende que gestores públicos são pessoas que ocupam função pública, podendo ser eleito ou não. Enquanto administrador público é aquele nomeado para um cargo público e atuante no serviço público.

Notou-se que o entrevistado 01 apresentou uma visão muito particular, quando afirmou que na atualidade, gestores e administradores públicos são eleitos e nomeados, pois na administração direta, os cargos de gestão acabam sendo cargos políticos e muitas vezes acomodações político-partidárias. Entende como ideal a abolição dos cargos de cunho político em prol da presença de profissionais na gestão da coisa pública.

Com comum opinião os entrevistados 03, 06 e 07 concordam que pode ser considerado gestor público àquele que por eleição, nomeação ou indicação, em caso de Cargo em comissão, exercer cargo público. Profissional este, segundo o entrevistado 03 que tem o papel de agente transformador na administração pública, podendo atuar nas áreas de planejamento, gestão de pessoas, administração financeira, entre outras. Considerando o agente eleito também um gestor, por lhe ser confiado à responsabilidade nos atos de sua gestão. 


\section{A CONTRIBUIÇÃO DO CURSO DE GESTÃO PÚBLICA DA UNIVERSIDADE FEDERAL DO PAMPA - \\ UNIPAMPA PARA A MODERNIZAÇÃO DA ADMINISTRAÇÃO PÚBLICA EM SANTANA DO \\ LIVRAMENTO/R \\ DOI: http://dx.doi.org/10.5007/1983-4535.2016v9n4p45}

A análise dos entrevistados mencionados encontra consonância em Silva (2011), que afirma ser gestor ou administrador público aquele designado, eleito ou nomeado formalmente.

Em resposta ao uso de tecnologias em apoio ao gestor público os entrevistados de forma consensual têm opinião de que as mesmas bem aplicadas, por profissionais capacitados que saibam ler e utilizar essas tecnologias possa segundo opinião do entrevistado 06 promover melhorias no processo de decisão e melhorar a comunicação entre órgãos e setores, que é uma grande dificuldade na administração pública municipal e na administração pública como um todo. De forma conciliatória o entrevistado 08 afirma que tais ferramentas podem agilizar os serviços públicos, gerando um maior número de informações para dados estatísticos e gerenciais na tomada de decisão.

Em colaboração a questão o entrevistado 07 vê os controles como forma de identificar e corrigir desvios, e complementa lembrando que a Lei de Responsabilidade fiscal, e outros controles, foram recomendados ao Brasil, pelo Fundo Monetário Internacional, em função dos gastos excessivos no setor público.

A opinião dos entrevistados concilia-se em Bittencourt e Zouain (2010) que afirmam que a profissionalização da gerência pública aliada a modernas tecnologias de gestão garantem a qualidade na aplicação de programas de governo e políticas públicas.

Com relação a essa questão, Paula (2010), dimensiona insuficiente a mera aplicação de novas técnicas administrativas ou a contribuição das mais modernas tecnologias, se na sua aplicação, implantação, condução e controle não houver um profissional especificamente capacitado, eticamente comprometido e conhecedor da estrutura pública, capaz de garantir ou comprometer todo um processo de mudanças ou adequações.

\subsection{HISTÓRICOS DA IMPLANTAÇÃO DOS CURSOS DE GRADUAÇÃO EM GESTÃO PÚBLICA EM SANTANA DO LIVRAMENTO}

Na concepção do entrevistado 08 não somente em Santana do Livramento, como em qualquer cidade brasileira, o conhecimento trazido pelo curso de gestão pública, contribui para a gestão das organizações públicas, que precisam estar abertas as mudanças que os egressos proponham implementar. Compartilhando desta opinião o entrevistado 01 afiança que para que as transformações ocorram é necessário uma aproximação das organizações e do curso, e uma abertura por parte das mesmas de espaço aos egressos. 


\section{A CONTRIBUIÇÃO DO CURSO DE GESTÃO PÚBLICA DA UNIVERSIDADE FEDERAL DO PAMPA - \\ UNIPAMPA PARA A MODERNIZAÇÃO DA ADMINISTRAÇÃO PÚBLICA EM SANTANA DO \\ LIVRAMENTO/R \\ DOI: http://dx.doi.org/10.5007/1983-4535.2016v9n4p45}

De forma positiva o entrevistado 02 vê o Curso de Gestão pública em Livramento como fator de motivação na busca de mudanças na forma de administrar a máquina pública, em prol do município. E afirma que o Curso já está empreendendo transformações na cidade através do trabalho que vem sendo desenvolvido pelos egressos em atividade na gestão municipal, que buscam trabalhar pelo progresso da cidade e maior qualidade de vida das pessoas. Em sentido concordante, porém ponderado o entrevistado 04 acredita nas transformações, embora perceba que essas modificações só poderão ser percebidas em médio prazo.

De acordo com a informação do entrevistado 07 o curso não foi implantado na busca de novos conhecimentos, mas criteriosamente, porque em quase todo país há falta de profissionais especializados nesta importante função; tanto que afirma o entrevistado, "um aluno formado nele pode trabalhar em qualquer parte da nação brasileira."

Nesse contexto, atesta o entrevistado, criou-se o Curso Tecnólogo em Gestão pública, porque se acreditava também que ele poderia empreender transformações nas organizações públicas do município e melhorar a compreensão daqueles que mesmo se formando no curso, não quisessem trabalhar como gestores públicos.

Tal questionamento e as colocações aqui apresentadas encontram embasamento em Girard (2009) que apresenta o conhecimento como um dos principais motivadores no processo evolutivo dos cursos de Gestão pública, e fator essencial ao desenvolvimento, sendo responsável por tornar as organizações mais competitivas. E em Bittencourt e Zenouin (2010) que consideram como elemento básico do progresso, além de um qualificado corpo de gestores públicos, auxiliares de funções executivas plenamente capacitadas.

Nesta busca por melhores condições de qualificar gestores e melhorar a administração pública local, passa-se a expressar a opinião dos entrevistados quanto à possibilidade de uma Escola de Governo e Cursos de qualificação nesta área, para o município.

Na concepção do entrevistado 08 as Escolas têm o papel de treinar e capacitar os servidores públicos na busca pela qualificação do serviço público oferecidos à população. A escola de governo agregaria muito para Santana do Livramento e demais cidades da região.

Em acordo com as ideias apresentadas pelos entrevistados, Levy (1997, apud BITTENCOURT E ZENOUIN, 2010), entende necessário, ao acompanhamento do Estado, através de uma nova visão de gestão, conjuntamente a uma política de formação permanente, que prepare seu pessoal, técnico-administrativo e gerencial, par o melhor desempenho da 


\section{A CONTRIBUIÇÃO DO CURSO DE GESTÃO PÚBLICA DA UNIVERSIDADE FEDERAL DO PAMPA - UNIPAMPA PARA A MODERNIZAÇÃO DA ADMINISTRAÇÃO PÚBLICA EM SANTANA DO LIVRAMENTO/R \\ DOI: http://dx.doi.org/10.5007/1983-4535.2016v9n4p45}

missão. Onde afirma que como forma de proporcionar qualificação, capacitação e treinamento ao setor público foram criados as "Escolas de Governo".

É entendimento da maioria dos entrevistados, que o curso tecnólogo procura preparar em menor tempo com igual qualidade, para uma rápida inserção no mercado de trabalho. Em termos curriculares, segundo a opinião do entrevistado 08 a diferença está na concentração de conteúdos e no menor tempo. Declara também que os cursos tecnólogos têm espaço nos diversos setores do mundo do trabalho.

No que se refere ao reconhecimento e espaço de trabalho, o entrevistado 07 considera que os alunos de Gestão Pública, graduados na UNIPAMPA foram prestigiados com cargos de confiança na atual administração pública o que denota um reconhecimento. Quanto ao espaço de trabalho, acredita que será maior quanto melhor for à gestão municipal e a atuação dos GP graduados em curso superior que lá trabalham.

Em relação ao reconhecimento e absorção, percebe o entrevistado 06 que a administração pública vem reconhecendo e absorvendo a existência desses profissionais em cargos em comissão, mas tem sido muito lento sua absorção no quadro efetivo por meio de concurso. Acredita que o aumento na oferta de cargos em concurso para gestor público é uma questão de tempo. De igual pensamento o entrevistado 03 entende que o mercado de trabalho está se adaptando para receber tais profissionais, e aponta que concursos na área que há pouco tempo não existiam tornam-se cada vez mais frequentes.

Este reconhecimento segundo opinião do entrevistado 05 acredita que já existe. Com referência ao espaço, não têm definido qual a função a ser exercida pelo gestor e sente preocupação com relação a absorção local, frente ao aumento de egressos do curso.

No entendimento do entrevistado 04 ainda existe uma cultura onde só é válido o ensino superior, entendido como os cursos tradicionais, de tal forma que os cursos tecnológicos têm um grande desafio na busca por reconhecimento e valorização.

De forma diferente o entrevistado 02 não sente haver por parte dos empregadores diferente tratamento ao tecnólogo ou ao bacharel, acredita o entrevistado que isso se deva a presença e familiaridade com a universidade e seus cursos.

De forma referencial, Bittencourt e Zouain (2010), dizem que a finalidade dos cursos de GP é o de suprir a necessidade de qualificação e capacitação daqueles que desenvolvem atividades nas diferentes esferas do serviço público, buscando atender ao constante crescimento do quadro de pessoal e o crescente interesse pela área. 


\section{A CONTRIBUIÇÃO DO CURSO DE GESTÃO PÚBLICA DA UNIVERSIDADE FEDERAL DO PAMPA - \\ UNIPAMPA PARA A MODERNIZAÇÃO DA ADMINISTRAÇÃO PÚBLICA EM SANTANA DO \\ LIVRAMENTO/R \\ DOI: http://dx.doi.org/10.5007/1983-4535.2016v9n4p45}

Com relação à distinção entre as formas de formação, Takashasi (2010) apresenta que os cursos voltados à formação para o trabalho, gestão de produção, serviços e à inovação científica e tecnológica, distinguem-se das graduações tradicionais por sua proposta e propósitos. Entende a autora que enquanto os cursos Tecnólogos buscam atender a demanda por uma área específica de conhecimento, caracterizada pela rapidez, foco e flexibilidade, as outras modalidades buscam formar generalistas. Estando todos aptos a dar continuidade a seus estudos em nível de pós-graduação.

Após analisados assuntos como o espaço de trabalho, reconhecimento dos cursos de gestão, passa-se a representar as concepções dos entrevistados quanto a modernização da gestão pública no Brasil.

\subsection{A MODERNIZAÇÃO DA GESTÃO PÚBLICA NO BRASIL A PARTIR DA DÉCADA DE 90}

É de entendimento do entrevistado 06 que os diferentes modelos coexistem, então os efeitos positivos e negativos permanecem. No caso do patrimonialismo, percebe-se ainda na conduta dos servidores a apropriação do Estado para fins privados, na burocracia há excessiva hierarquização, bem como controles que tornam os processos ineficientes e o gerencialismo enfrenta a falta de transposição gerencial para o contexto da administração pública, ou seja, faltam ferramentas de gestão próprias para a cultura das organizações públicas.

$\mathrm{Na}$ visão do entrevistado 01 Santana do Livramento ainda vive o deslocamento dos modelos patrimonialista e burocrático para o gerencial. Ainda estamos em fase de adequação. Como ponto negativo aponta o fato das negociações político-partidárias, colocando indivíduos em cargos para os quais não estão preparados, por acomodação política. Em contraponto percebe-se o interesse dos últimos governos em fazer adequações, buscando a profisssionalização da Gestão Pública.

Entre os principais problemas locais, o entrevistado 07 coloca a falta de planejamento e o clientelismo de forma evidente na gestão pública em Santana do Livramento.

Matias (2012) associa a história da Gestão Pública no Brasil à própria evolução da administração pública, com sua trajetória identificada nos diferentes modelos utilizados na administração pública brasileira.

Dentro desse contexto acompanha-se a seguir as colocações dos entrevistados a respeito das conquistas e limitações vividas nos anos 90 em termos de gestão pública. 


\section{A CONTRIBUIÇÃO DO CURSO DE GESTÃO PÚBLICA DA UNIVERSIDADE FEDERAL DO PAMPA - \\ UNIPAMPA PARA A MODERNIZAÇÃO DA ADMINISTRAÇÃO PÚBLICA EM SANTANA DO \\ LIVRAMENTO/R \\ DOI: http://dx.doi.org/10.5007/1983-4535.2016v9n4p45}

Em resposta aos questionamentos propostos o entrevistado 07 entende que todos os municípios tiveram que respeitar legislações, inclusive Livramento, onde como principais inovações ressaltam a Lei de Responsabilidade Fiscal (LRF), e o Controle Interno.

O entrevistado 03 diz que "a administração pública no município não pode ser considerada gerencial, ela é ainda muito burocrática”. Na concepção do entrevistado 01 este não foi um fator determinante, visto que de 90 pra cá tivemos que conviver com governos patrimonialistas, democráticos e com vieses coronelistas. A nossa convivência com governos ditos populares, é recente, e a própria sociedade santanense ainda confunde Políticas Públicas e Serviços sociais com assistencialismo.

Para o entrevistado 08, O plano Diretor da Reforma do Estado foi um ponto determinante para a modernização da administração pública, no entanto sobre a modernização da administração pública em Santana do Livramento não tem uma opinião formada.

Abrúcio (2007) aponta como principais conquistas desse período a reorganização administrativa do governo federal, concursos e a revitalização das capacitações promovidas pela ENAP, instituição de tetos aos gastos com o funcionalismo, introdução do princípio da eficiência, criação das Organizações Sociais - OS's e Organizações da Sociedade Civil de Interesse Público - OSCIP's.

$\mathrm{Na}$ opinião do entrevistado 01 , não só como fator motivador, mas como instigador da modernização e melhorias. O curso de gestão pública tem muito a evoluir, e o entrevistado afirma querer usufruir dessa evolução. Espera também que os espaços sejam ocupados pelos gestores egressos do curso de GP, e que estes, saibam aplicar o conhecimento adquirido na Academia.

Para o entrevistado 06 a sociedade de Santana do Livramento, ainda não tem maturidade para participar, os espaços de participação como os conselhos são espaços esvaziados, bem como audiências públicas que tratam da prestação de contas. É um processo lento de transformação social, que o Curso tende a contribuir.

Também no entendimento do entrevistado 05 a participação da população ainda é muito tímida, não comparecem as audiências públicas, não fiscalizam. Só se mobilizam se comandados, ou seja, por influência política.

A percepção apresentada pelo entrevistado 03 é de que a participação mais ativa dos conselhos, transparência, prestação de contas, trarão mais motivação e credibilidade a administração pública e por consequência modernização dos serviços prestados. 


\section{A CONTRIBUIÇÃO DO CURSO DE GESTÃO PÚBLICA DA UNIVERSIDADE FEDERAL DO PAMPA - \\ UNIPAMPA PARA A MODERNIZAÇÃO DA ADMINISTRAÇÃO PÚBLICA EM SANTANA DO \\ LIVRAMENTO/R \\ DOI: http://dx.doi.org/10.5007/1983-4535.2016v9n4p45}

Assim ao findar-se a apresentação e análise das entrevistas contextualizadas com as afirmações dos autores que referenciaram este estudo, apresentar-se-ão as considerações finais.

\section{CONSIDERAÇÕES FINAIS}

Atendendo o objetivo geral deste estudo, que foi identificar a contribuição do curso de Gestão Pública da UNIPAMPA para a modernização da Administração Pública em Santana do Livramento, vê-se que na percepção de professores, ex-alunos e secretários municipal, com relação às diferenças entre gestão pública e administração pública o tema divide a opinião dos entrevistados, sendo que enquanto alguns entrevistados concebem como gestor público somente àquele nomeado e por concurso público. A maioria percebe, assim como o autor citado, que as três formas de ingresso na administração pública são legítimas. No âmbito municipal defendem a efetivação do cargo por concurso público como forma de trazer maior qualidade a administração pública municipal, atendendo às demandas sociais $E$ muito embora na visão dos respondentes existam três formas de ingressar na vida pública, por concurso, por eleição, e por indicação e a percepção da maioria dos entrevistados está em conformidade com um dos autores citados.

Porém, há uma polêmica grande em torno do acesso a administração pública por meio de eleição, visto que se a ideia é tornar a administração Pública mais eficiente e eficaz, parece que o concurso é o melhor caminho. Assim como o autor citado, que as três formas de ingresso na administração pública são legítimas. No âmbito municipal defendem a efetivação do cargo via concurso público, como forma de trazer maior qualidade a administração pública municipal, atender às demandas sociais, com a autonomia que the concede a legislação e fazendo uso dos conhecimentos adquiridos, para melhor gerir os recursos existentes.

Quanto ao histórico da implantação dos Cursos de Graduação em Gestão Pública em Santana do Livramento, percebeu-se que além dos fatores que motivaram a sua implementação e disseminação no país, em outras instituições de ensino superior, foram: os de preparar de forma mais rápida, porém qualificada profissionais para um mercado de trabalho emergente, dentro de um contexto econômico globalizado. Especificamente o Curso de Gestão Pública da UNIPAMPA, foi implantado a partir de criteriosa análise, que apontou para a necessidade e carência de cursos voltados à profissionalização da administração pública em todo país, e pela possibilidade de transformações e melhorias advindas da 
formação de gestores públicos e da aplicação desses conhecimentos no município e em toda região, visto ser este um dos três únicos Cursos Tecnólogos em Gestão Pública, em instituições federais no Estado do Rio Grande do Sul.

Com relação à modernização da Gestão Pública no Brasil, a partir da década de 90 , verificou-se que ela busca e divide espaço com os remanescentes modelos de administração pública que coexistem e em muitos aspectos predominam em grande parte do país. Como por exemplo, em termos municipais a percepção dos entrevistados desenha um cenário, onde a modernização e a nova gestão pública ainda não conquistaram espaço. Com uma administração pública marcada por traços patrimonialistas, excesso de burocracia e falta de planejamento, que só implanta inovações advindas das obrigações, e busca timidamente formas de obter melhorias e modernização aos serviços públicos e a forma de administrar o município.

Diante disto, Como resultado, identificou-se que, hoje a contribuição do curso de Gestão Pública da UNIPAMPA tem sido essencial para a busca de melhorias na prestação de serviços da Prefeitura Municipal de Santana do Livramento, sendo esta instituição a mais beneficiada tanto com a produção acadêmica do Curso de Gestão Pública, quanto com o aproveitamento de egressos. A urgente necessidade de qualificar e capacitar os administradores públicos locais fez surgir o interesse por formação continuada dos gestores públicos locais, sendo atualmente ofertado também o Cursos de Pós-graduação Lato Sensu. Tal fato constitui-se em verdade a partir do momento que após a formação da primeira turma de Gestão Pública a Prefeitura Municipal de Santana do Livramento abriu edital de concurso para contratação de gestores públicos.

Ao final deste estudo recomenda-se que a Administração Pública local abra mais suas portas para que a UNIPAMPA tenha nos órgãos públicos locais espaço para o desenvolvimento de atividades prática para seus alunos. Feito isto ambas as partes, entende-se ganharão, tendo-se a formação de futuros gestores públicos mais conscientes da realidade e a Administração Pública mais próxima de Teorias que conduzem efetivamente à eficiência e eficácia.

\section{REFERÊNCIAS BIBLIOGRÁFICAS}

AMARAL, H.K. Apresentação à Edição Brasileira. In PETERS, B. G e PIERRE, J. São Paulo: UNESP, 2010. 
B. Guy Peters; PIERRE, Jon. Administração Pública Coletânea. Brasília, DF: ENAP, 2010.

BERGUE, Sandro Trescastro. Gestão de Pessoas em Organizações Públicas. 3.ed. Ver. Atual. Caxias do Sul: EDUCS, 2010.

BRASIL, Constituição Federal (1988). Artigo n 37 de 05 de outubro de 1988. Disponível em: $<$ http://www.planalto.gov.br/ccivil 03/constituicao/constituicao.htm $>$ Acesso em: 02 de agosto de 2013.

DIAS, Emerson de Paulo. Conceitos de Gestão e Administração: Uma Revisão crítica. Revista Eletrônica de Administração - Facef. Vol.01. Edição 01. 2002. Disponível em: < http://periodicos.unifacef.com.br/index.php/rea/article/view/160/16> Acesso em: 18 de janeiro de 2014.

DENHART, ROBERT B. Teorias da Administração Pública. SÃO PAULO: Cengage Learning, 2010.

FOUREZ, G. A construção das ciências: introdução à filosofia e a ética das ciências. TradLuiz Paulo Rouanet. 1 ${ }^{\text {a }}$ Reimpressão. São Paulo: Unesp, 1995.

GIL, Antonio Carlos. Como Elaborar Projetos de Pesquisa. 5.ed. São Paulo: Atlas, 2010.

LYNN, L. JR.; HEINRICH, C. J.; HILL, C. J. Improving Gevernance: A New Logic for Empirical Research. Washington, DC: Georgetown University Press, 2001.

http://www.centropaulasouza.sp.gov.br/pos-graduacao/workshop-de-pos-graduacao-epesquisa/anais/2011/trabalhos/formacao-profissional-etecnologica/Pol\%C3\%ADticas\%20de\%20Forma\%C3\%A7\%C3\%A3o\%20Tecnol\%C3\%B3gi ca\%20(1942-2006).pdf em 06/02/2014.

MILLET, John D. Manangement in the Public Service. New York: McGraw-Hill, 1954.

NASCIMENTO, Edson Ronaldo. Gestão Pública Aplicada: União, Estados e Municípios, gestão pública no Brasil, de JK a Lula, gestão orçamentária e financeira, a gestão fiscal responsável, tributação e orçamento, tópicos especiais em contabilidade pública, gestão das contas nacionais, gestão ecológica e ambiental. -2. ed. rev. e atualizada. -São Paulo: Saraiva 2010.

PAES DE PAUlA, A. P.. Por uma Nova Gestão Pública. São Paulo: FGV, 2005.

http://porteiras.unipampa.edu.br/livramento/index.php?option $=$ com content\&view $=$ article\&id $=45 \&$ Itemid $=54$ 24/02/2014.

SAMPIERI, Roberto Hernández; COLLADO, Carlos Fernández; LUCIO, Pilar Baptista. Metodologia de pesquisa. São Paulo: McGraw-Hill, 2006.

WILLIAMS, Chuck. Adm/Chuck Williams. Tradução Roberto Galman; Revisão técnica Sérgio Lex. São Paulo: Cengage Learning, 2010. 
TAKAHASHI, Adriana Roseli Wunsh. Cursos superiores de tecnologia em gestão: reflexões e implicações da expansão de uma (nova) modalidade de ensino superior em administração no Brasil. Rev. Adm. Pública vol.44 no.2 Rio de Janeiro Mar./Apr. 2010. Disponível em: < http://www.scielo.br/scielo.php?pid=S0034-

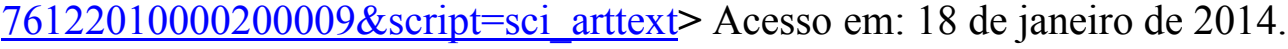

